\title{
The model for cylinder charge parameters during engine starting
}

\section{ARTICLE INFO}

Received: 2 August 2021

Revised: 24 August 2021

Accepted: 8 September 2021

Available online: 17 September 2021
The process of cylinder charge - air sucked into the cylinder - transformation during engine start-up phase is characterized. Heat exchange and air flow through piston-cylinder group leakage processes are described as factors influencing the gas thermodynamic parameters. The Woschni formula based on similarity theory was finally used as equation describing heat transfer in combustion engines cylinder. The computational model for cylinder charge parameters in the whole engine cycle during its starting at low temperature is presented. Some taken assumptions and characteristics of partial processes resulting from the computations are shown. There are indicated the possibilities of using the model at internal combustion engine diagnostic process.

Key words: combustion engine, low temperature start-up, cylinder charge parameters

This is an open access article under the CC BY license (http://creativecommons.org/licenses/BY/4.0/)

\section{Introduction}

It is known that difficulties in obtaining the start of piston combustion engines increase at lowered temperature conditions. Lowering abilities of a diesel engine to undertake the independent operating at low temperature result from its influence on exploitation materials, engine systems properties, and directly from lowering the temperature of the air sucked-up into the engine cylinders. In the first phase of a difficult start the starter drives the engine crankshaft with a certain rotational speed. Then in the engine cylinders there are no ignitions of the injected fuel, but there are created the conditions suitable for its appearing. The requirement of the engine start-up is to initiate a cyclical, automatic repetition of the combustion processes in cylinders. There are two factors deciding of the injected fuel combustion occurrence: thermodynamic parameters (temperature and pressure) of air charge in the engine cylinders and the fuel spraying quality [4]. Thus, the knowledge about the thermodynamic state of the charge contained in engine cylinders is important for evaluation of air-fuel mixture properties and combustion processes characteristics during engine starting. It was the reason for which a model for cylinder air charge in starting conditions has been worked out.

The problems of engine start-up mathematical modelling have been widely discussed, e.g. $[1,5,11,18]$. Computation procedures include a considerable number of parameters resulting from experimental data or complete experiment enabling to receive additional information basing on an indicator diagram. One of the most important parameters of such a model is the heat transfer coefficient of the air charge with the cylinder walls. The first heat transfer equation for combustion engines based on similarity theory was formulated by Woschni. It is still in use today [12]. There are also presented the new heat transfer correlations for the Engines [2]. In the paper [6] there is done the modified wall heat transfer equation which correctly reflects the transient, spatially averaged wall heat losses for SI-engines and DIdiesel combustion engines without any adjustments of empirical calibration factors.
These correlations are used in models for engine starting conditions. Effects of cold start control strategy on cold start performance of the diesel engine based on a comprehensive preheat diesel engine model are presented in [3]. The change in the temperature field of the charge at compression was numerically studied [9], taking into consideration the vortex flows that arise when a charge forms in the engine's cylinder. It was necessary to substantiate the new method for facilitating the cold start of the diesel engine. The paper [14] presents the different issue of thermal loads of a piston in a combustion engine during start-up. There were conducted simulation research based on the results of engine tests in the low temperature test chamber. There are also presented in the literature [8] the results of in-cylinder measurements of gas temperatures and pressures during a cold start.

It could be necessary to tune the coefficients of empirical formulas during the model calibration process if a formula is not accurate enough in the case of a specific combustion engine [19]. In the case of commercially available software the capability of the standard heat transfer models is limited due to model calibration constrains. It is possible to increase the capability of the simulation tool using the user model linked to the main solver or constituting an independent, own solution of the author prepared for a specific purpose.

The article presents such author's own study of the model for cylinder charge parameters during engine starting - cranking by the starter system designed for enginebattery-starter system diagnosis.

\section{Cylinder air charge changes in engine starting conditions}

In the case of a diesel engine starting the fuel autoignition may occur if in the compression process the air charge reaches the suitable values of thermodynamic parameters and appropriate fuel atomizing appears. The autoignition process of the sprayed fuel is characterized by selfignition delay. The autoignition delay is a function of the temperature and pressure and increases when their values decrease. That is why it is necessary to know air charge parameters 
during engine starting. The gas transformation process can be described using the energy conservation law - often called the first thermodynamic law in the differential form for an open system:

$$
\mathrm{dU}=-\mathrm{pdV}+\mathrm{dQ}+\mathrm{idm}
$$

where: $d U=m d u+u d m-$ air charge internal energy change, pdV - elementary work of volume change, dQ heat quantity exchanged between air and the walls surrounding it, $\mathrm{i}$ - specific gas enthalpy $(\mathrm{I}=\mathrm{U}+\mathrm{pV})$.

The gas total energy change and charge parameters at any moment of the process can be evaluated by equation (1) integration. The quantity of exchanged heat can be specified applying expression:

$$
\mathrm{Q}=\int \mathrm{dQ}=\iint_{\mathrm{Ft}} \alpha\left(\mathrm{T}-\mathrm{T}_{\mathrm{S}}\right) \mathrm{dF} \mathrm{dt}
$$

where: $\alpha$ - the surface film conductance, $\mathrm{F}$ - the surface of heat exchange, $\mathrm{T}-$ the air temperature, $\mathrm{T}_{\mathrm{S}}-$ the temperature of the surface surrounding the air volume, $\mathrm{t}-$ the heat exchange time.

The fundamental importance for the heat exchange processes between air charge and the piston, engine head and cylinder walls has the choice of an appropriate formula describing surface film conductance value. There are wellknown many empirical formulae for computing its value in engine compression chambers (for example formulae according to Woschni and Zapf) [16]. They usually have a similar general character (they differ only with constant parameters values):

$$
\alpha=\mathrm{A}\left(\mathrm{v}_{\mathrm{t}} \mathrm{p}\right)^{\mathrm{a}}(\mathrm{d})^{\mathrm{b}}(\mathrm{T})^{\mathrm{c}}
$$

where: A, a, b, c-constant parameters, $\mathrm{v}_{\mathrm{t}}$ - average piston speed, $\mathrm{d}$ - cylinder diameter.

There was carried out the analysis of some formulae of this type. The course of computed, using some formulae, surface film conductance values as a function of crankshaft rotation angle are presented in Fig. 1. During the computations there were taken the same values of air temperature and pressure for each formula and technological data for AD4.236 engine. In the Sitkei formula d does not mean the cylinder diameter but the so-called equivalent combustion chamber diameter evaluated as: $d=2 \mathrm{Dh} /(\mathrm{D}+2 \mathrm{~h})$, where $\mathrm{D}$ is the cylinder diameter and $\mathrm{h}$ the height of the combustion chamber over the piston. The dependence presented in [1] is very different in its character:

$$
\alpha=406 \cdot \rho^{0,4} \quad\left[\frac{\mathrm{W}}{\mathrm{m}^{2} \cdot \mathrm{K}}\right]
$$

The air density is in $\left[\mathrm{kg} / \mathrm{m}^{3}\right]$. This formula gives much more enlarged surface film conductance values equal 460 to $980\left[\mathrm{~W} /\left(\mathrm{m}^{2} \cdot \mathrm{K}\right)\right]$ in the conditions assumed for the discussed computations.

Taking into account that the Zapf formula gives enlarged values of the surface film conductance, and it was elaborated in principle for cylinder charge exchange periods, but Sitkei formula gives its values a bit decreased, for the subsequent considerations (after some verifications) there was accepted the Woschni formula.

In each engine operating conditions a part of the compressed air charge flows to the crankcase through piston- cylinder group leakage. The proportion of this part of charge is higher when the rotational speed of engine crankshaft is lower, especially in the range of speed extorted by starter. Because of it the air flow in crankshaft driving conditions should be taken into account.

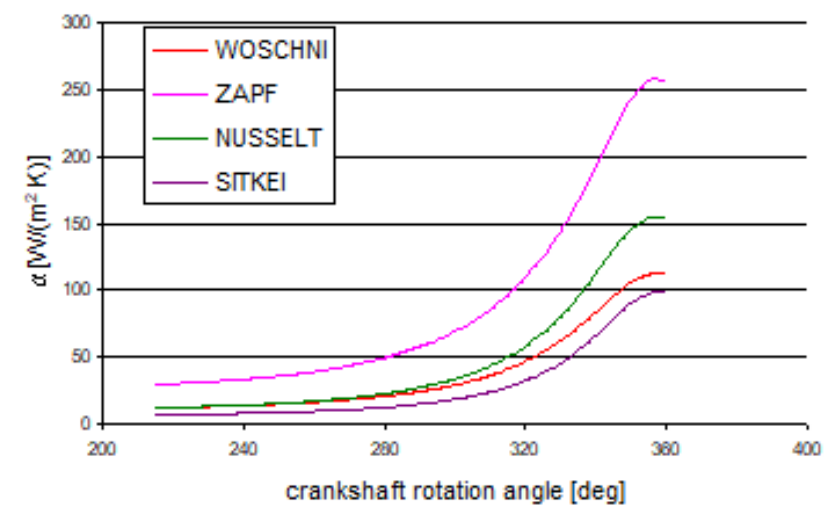

Fig. 1. The dependence of surface film conductance value on crankshaft rotation angle in AD4.236 engine compression chamber computed according to the formulae of: Zapf, Nusselt, Woschni, Sitkei

Application of an appropriate formula and constant parameter for describing the air flow through piston-cylinder leakage is also important. The air flow can be treated as an incompressible viscous fluid flow by the speeds of $0,6 \mathrm{M}$ (Mach) [17]. Then the flow is expressed by a formula describing the equilibrium of static and dynamic pressure in chosen pipe section where the flow exists:

$$
\Delta \mathrm{p}=\frac{1}{2} \xi \cdot \rho \cdot \mathrm{w}^{2}
$$

where: $\xi$ - the coefficient of flow drag, $\rho$ - density of the flowing fluid, $\Delta \mathrm{p}$ - static pressures difference between the ends of pipe, $\mathrm{w}$ - velocity of fluid flowing.

From this it is possible to determine the flowing fluid velocity:

$$
\mathrm{W}=\sqrt{\frac{1}{\xi}} \sqrt{\frac{2 \Delta \mathrm{p}}{\rho}}=\mu \sqrt{\frac{2 \Delta \mathrm{p}}{\rho}}
$$

where: $\mu$ is the intensity of flow coefficient.

There is used one orifice as a model of air flow. By the high pressure difference between engine cylinder and crankcase volume, the air flow should be treated as supercritical viscous fluid flow. In this case the speed of air flowing to the crankcase can be evaluated on the base of energy conservation law. For the isentropic flow of compressive fluid, by assumption that the initial fluid speed equals " 0 ", the final speed $w$ can be computed as [16]:

$$
w=\sqrt{2 \frac{\kappa}{\kappa-1} p_{1} v_{1}\left[1-\left(\frac{p_{2}}{p_{1}}\right)^{\frac{\kappa-1}{\kappa}}\right]}
$$

where: $\kappa-$ the average value of adiabatic exponent, $v_{1}-$ the initial specific volume of flowing fluid, $\mathrm{p}_{1}$ - initial static pressure of the fluid, $\mathrm{p}_{2}-$ the static pressure in the final flowing section.

It is necessary, for the real viscous fluid flow, to introduce into the equation (7) the coefficient of flow velocity 
(because of friction losses). This coefficient is experimentally determined for a given orifice. For model needs there was defined the specific (unitary) linear coefficient of volume flow intensity $-\mu_{1}$. " $\mu_{1}$ " is the only one constant parameter in the model (apart from the formula describing the heat exchange process), which is determined using the experimental data. So, the elementary air volume $\Delta \mathrm{V}$, which flows through piston-cylinder leakage at $\Delta \mathrm{t}$ time can be determined as:

$$
\Delta \mathrm{V}=\mu_{1} \pi \mathrm{d} \Delta \mathrm{tw}
$$

\section{Computational model characteristic}

The presented model is a numerical approach using integration procedures of the first thermodynamic law (1). The computations are realized by iteration method, where computing accuracy is obtained in the internal cycle. The model initial basic assumption is that the temporary rotational speed of the crankshaft has a constant value. The values of parameters characterizing air physical properties, depending on a chosen computing option, can be taken as constant or dependent on its temperature and pressure (air specific heat by constant volume $c_{v}$, adiabatic exponent $\kappa$, air density). Piston relocation and substitute height of combustion chamber are determined according to the kinematic dependences for piston-connecting-rod system. As the initial piston location ( 0 degrees of crankshaft rotation) its TDC at the beginning of intake stroke was taken.

Moreover, there were made some additional assumptions in the model, such as:

1. cylinder charging with fresh air and gas outflow are processes which proceed at a constant pressure value equal to the ambient pressure,

2. at the moment of the exhaust valve opening the immediate pressure equalization between cylinder charge and engine ambient takes place (gas being present in cylinder is subjected to the adiabatic process and a suitable mass of air flows into the cylinder).

Depending on the chosen option the computer program can realize the following procedures:

- gas adiabatic process by iteration method or RungeKutt's approach and comparing the results with the computed parameters using the adiabatic equation,

- gas change process at engine start-up conditions with taking into account (or not) heat exchange and blow-by of gas processes,

- evaluation of the engine minimum starting rotational speed dependence on temperature.

The input data include technological data concerning the engine, initial parameters of air and the engine, and conditions for processes involving the air. Output data include the current parameters of air charge in cylinder, such as temperature, pressure, temporary value of surface film conductance and specific heat, mass of the air charge. Moreover, there are computed some summarizing data, for example the average equivalent value of polytropic exponent for compression and decompression processes. Computation results can be presented on a computer display screen, printer or text file and then be transformed using computer software.

\section{Initial verification of the model}

The main goals of the initial model verification were to evaluate, which of the partial processes have a decisive influence on charge parameters and to evaluate specific (unitary) linear coefficient of volume flow intensity. The presented results concern the diesel engine AD4.236 of a farm tractor, which was also experimentally tested. Computations were carried out for the data:

- inlet air temperature $-260 \mathrm{~K}$,

- ambient pressure -1 atm $=0.101325 \mathrm{MPa}$,

- average crankshaft speed - $120 \mathrm{rpm}$.

The accepted above for computations value of rotational speed of the crankshaft is due to the fact that driven by the starting system crankshaft speed varies significantly from about $80 \mathrm{rpm}$ for compression ignition engines and from 40 rpm for spark ignition engines to about $300 \mathrm{rpm}$ [13].

For evaluation, which factor has a decisive influence on air parameters in engine cylinder, there were carried out different computational processes of air parameters change applying the discussed model.

In Fig. 2 there are presented the results of computed temperature values for various types of cylinder charge change:

1. adiabatic process without taking into account the temperature influence on air specific heat and adiabatic exponent $(\kappa=$ const $=1.4)-$ marked with a in Fig. 1 ,

2. adiabatic process with taking into account the temperature influence on air properties (specific heat and adiabatic exponent) $-\mathrm{b}$,

3. change process with taking into account the heat exchange between air charge and the walls surrounding it according to Woschni formula (and temperature influence on air properties) - c,

4. change process with taking into account the heat exchange according to Woschni formula and blow-by of gas by leakage of the piston-cylinder group -e.

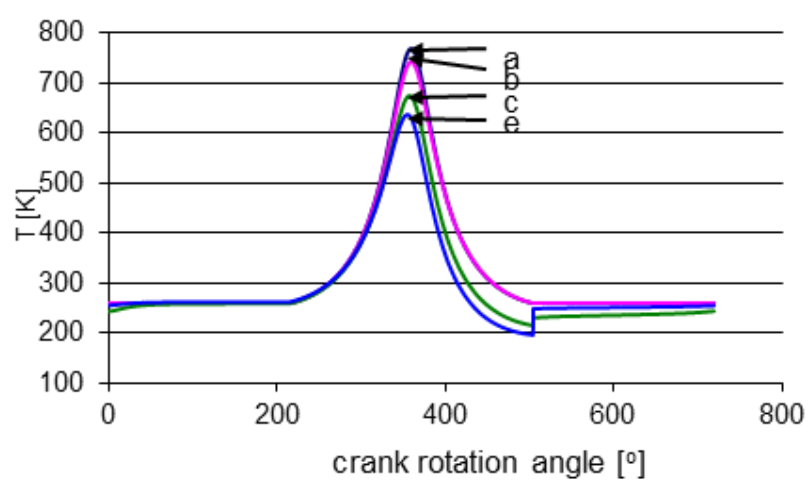

Fig. 2. The results of air temperature computation for various charge changes in AD4.236 engine cylinder

It is necessary to underline the change of air temperature values at the moment of outlet valve opening for gas change processes with taking into account the heat exchange and gas flow through leakage (curve e). At the final period of air charge decompression stroke its temperature and pressure decrease till much lower values than parameters of the engine environment. In this case the charge tem- 
perature before outlet valve opening equals about $194 \mathrm{~K}$, so it is $66 \mathrm{~K}$ lower than ambient temperature.

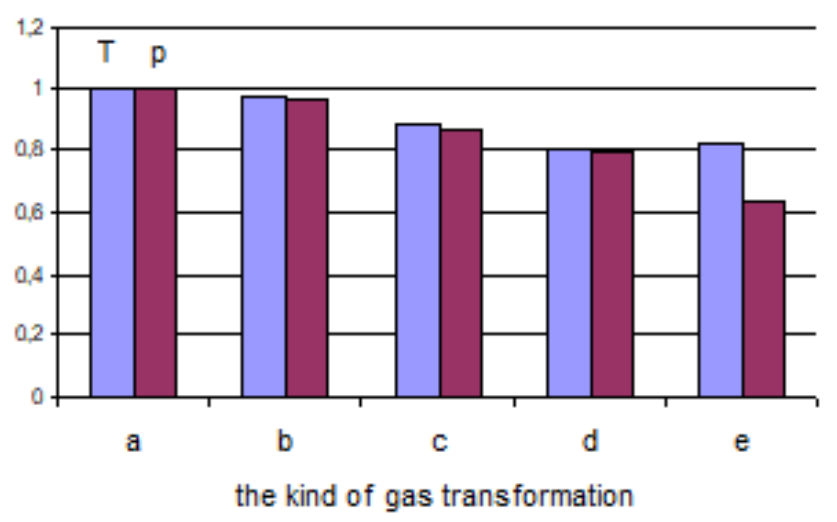

Fig. 3. The quotient values of temperature and pressure for different types of air change in comparison to adiabatic process at piston location in TDC

The comparative data illustrating the temperature and pressure quotient values for every type of change in comparison to their value in the adiabatic process with adiabatic exponent $\kappa=$ const $=1.4$ at piston location in $\operatorname{TDC}\left(360^{\circ}\right)$ are presented in Fig. 3. In this figure there are also presented data for process in which there were taking into account the heat exchange according to Zapf formula $-\mathrm{d}$. The presented dependences indicate the degree of individual factor influence on computed thermodynamic gas parameters.

It is worth noticing that taking into account only the temperature influence on air properties causes the noticeable decrease of cylinder charge thermodynamic parameters. Heat exchange phenomenon causes air charge temperature and pressure lowering, in comparison to adiabatic process, practically at the same degree. Air flow through pistoncylinder group leakage influences the temperature and pressure values obtained during air transformation in engine cylinder at different degree. The fact that heat exchange and gas flow influence air charge thermodynamic parameters at different degree can be useful in independent determining constant parameter values which characterize these processes in crankshaft driving conditions. It is important that the equivalent compression polytropic exponent for air change, where surface film conductance is described with Zapf's formula without additional air flow through leakage is lower than during the process described by Woschni formula and taking into account mass losses (in Fig. 3 the quotient of air temperature in $\mathrm{d}$ is lower than in e case). There was made an attempt to determine the reason for difference of surface film conductance expressed by Woschni and Zapf formulae. The different values of this parameter cause visible difference between air parameters obtained using the two formulae. In Fig. 4 there is presented the course of their quotient values as crank angle function in the case if constant $\mathrm{A}$ in both formulae has the same value and surface film conductance was evaluated for the same values of air temperature and pressure.

It is easily seen that the basic reason for the difference between both coefficients of surface film conductance are various values of constant $A$. If the constant $A$ has the same value, the highest relative difference of temperature values in the processes described by such dependences does not exceed $3.5 \%$. The criterion for determining the specific (unitary) linear coefficient of volume flow intensity $-\mu_{1}$ was the equality of air charge maximum pressure evaluated using the model and the one determined experimentally.

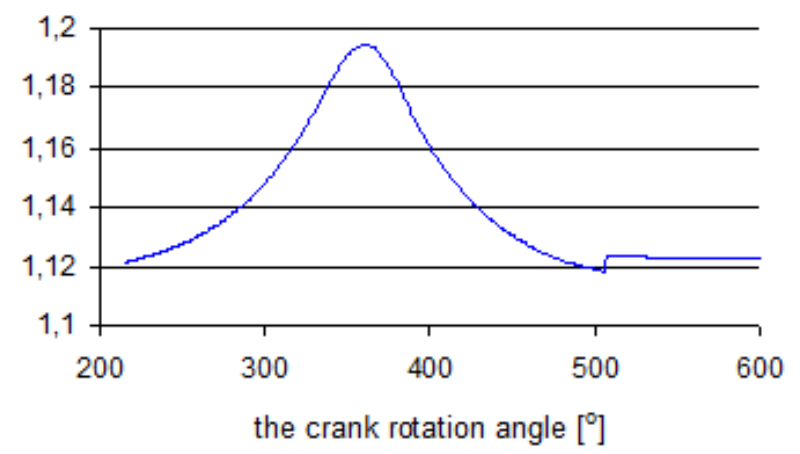

Fig. 4. The quotient values of temperature and pressure for different types of air change in comparison to adiabatic process at piston location in TDC

It is easily seen that the basic reason for the difference between both coefficients of surface film conductance are various values of constant $A$. If the constant $A$ has the same value, the highest relative difference of temperature values in the processes described by such dependences does not exceed $3.5 \%$. The criterion for determining the specific (unitary) linear coefficient of volume flow intensity $-\mu_{1}$ was the equality of air charge maximum pressure evaluated using the model and the one determined experimentally.

The final verification concerns the influence of the kind of air flow through the leakage and the temporary crankshaft speed changes on the computation results. Because the crankshaft rotational speed cannot be computed using the model (because of lack of suitable experimental data), there were taken into account the results of its measurements. Because the difference in obtained results are difficult to distinguish in the complete diagram of engine cycle, in Fig. 5 there is presented a fragment of the course of the computed charge temperature values (in the surroundings of TDC) for the different conditions of air flow through pistoncylinder group leakage and the changes of temporary crankshaft speed:

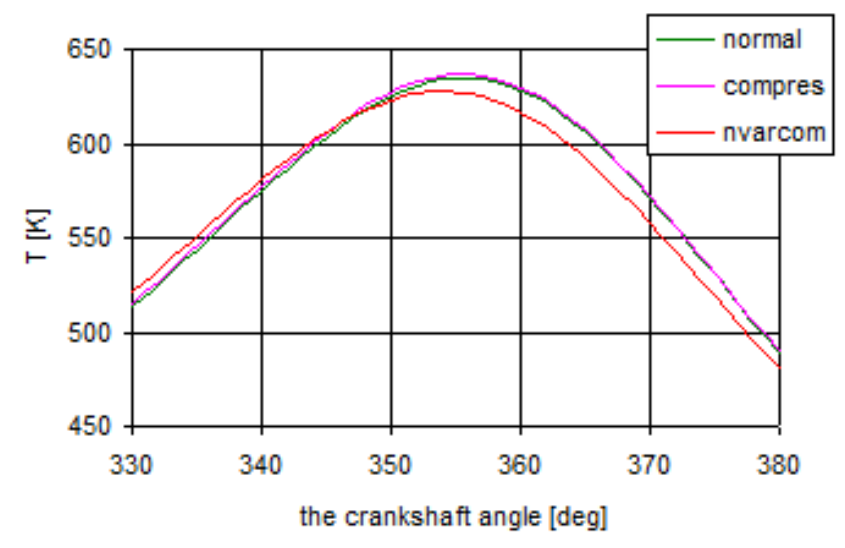

Fig. 5. The fragment of the computed temperature values dependence on the crankshaft rotation angle for different conditions of air flow and crankshaft temporary rotational speed changes 
- normal - incompressible fluid flow, constant crankshaft rotational speed value,

- compres - compressible fluid flow, constant speed value,

- nvarcom - compressible fluid flow, changeable speed value.

It was necessary to assume the appropriate specific linear coefficient of volume flow intensity value for each examined process according to the maximum pressure criterion.

It is easily seen that in the crankshaft rotation angle interval, in which the processes of creating and ignition of air-fuel mixture take place, the differences between the computed temperature values are inconsiderable. So, independently of the assumed rules of air flow and the crankshaft temporary speed changes the obtained results, in aspect of the air temperature influence on engine starting properties, are comparable. The maximum relative differences of the parameters values characterizing the air change processes in relation to the process with incompressible air flow are:

- for the process taking into account the compressible fluid flow at constant speed value: temperature $-0.55 \%$, pressure $-2 \%$ (after TDC, about $430 \mathrm{deg}$ ), mass losses $-1.5 \%$,

- for the process taking into account the compressible fluid flow at changeable speed value: temperature $2.3 \%$, pressure $-9 \%$ (after TDC, about $430 \mathrm{deg}$ ), mass losses $-8 \%$ (about $430 \mathrm{deg}$ ).

\section{Using the model in engine diagnostic process}

As it was marked before, the developed and presented model for cylinder charge parameters during engine crankshaft driving could be used for engine-battery-starter system diagnosis, especially for analysis of the compression in the cylinders of an internal combustion engine. Changes in tightness of an internal combustion engine combustion chamber may be determined based on: the measurement results of maximum compression pressure in the cylinders, pressure drop measured using a cylinder leakdown tester, and the blow-by flow rate at different engine operating conditions. Also, the comparative compression in the cylinders of an engine may be tested by analyzing the changes of current drawn from battery when the engine is cranked by the starter motor with ignition or fuel inhibited.

Each engine cycle has a positive current peak due to a compression stroke in specific cylinder. Missing a positive current peak indicates a very low compression in one cylinder. The current cycles could be integrated and the integrals compared to detect compression imbalance. The base level of integration is equal to the level of an adjacent negative current peak (see Fig. 7). In the same way for engine cylinders relative compression diagnosis can be used battery voltage [7] or even engine crankshaft rotational speed, in inverse relationship of the positive and negative peaks. The analysis of the possibility of using the results of measurements of the instantaneous rotational speed and its derivative - crankshaft acceleration to assess the condition of a compression-ignition engine is presented in [15].

For the purpose of internal combustion engine diagnostics, there are new possibilities to use the parameters of crankshaft driving by the electric starting system: the cur- rent drawn by the starter, the voltage at the battery terminals, the crankshaft rotational speed. For the diagnostic use of these parameters it is necessary to build mathematical models of all objects - especially cylinder charge transformation process. The intensity of the current consumed by the starter, the voltage at the battery terminals and the rotational speed of the crankshaft are the response of the engine-starter-the starting battery set to the forcing, which is the internal combustion engine crankshaft driving by the starter. In the diagnostic test, the values of the system's state characteristics should be determined on the basis of the features of the output signals - system response to external extortion, which include:

- the intensity of the current consumed by the starter - it characterizes the battery's ability to return current under load conditions, it depends on the state of the starter characterizing the relationship between the current consumption and the generated torque, contains information about the combustion engine resistance of motion,

- voltage at the loaded battery (or starter) terminals - it contains information on the state of the energy source feeding the starter. The voltage value is dependent on the nominal battery capacity, current consumption, temperature and its status,

- rotational speed of the crankshaft forced by the starter it is the resultant of the following features: the engine motion torque of resistance, the electromechanical characteristics of the starter and the starting capacity of the battery.

The variable component of the engine resistance torque, when the crankshaft is driven by the starter, depends on the compressed air pressure in the engine cylinders. An example of the course of the charge pressure in the engine cylinder during crankshaft driving is shown in Fig. 6.

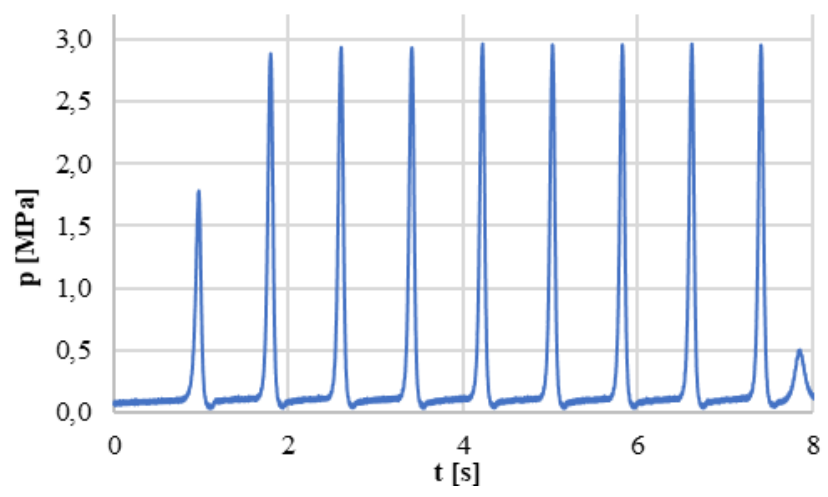

Fig. 6. The course of the compression pressure in the cylinder of the engine being tested

The variable component of the starter current (resistance torque) can be the premise for determining the value of the air compression pressure in the engine cylinders. To determine the value of the compression pressure, it is necessary to build a model for the engine crankshaft driving that allows correlating the pressure value and the current drawn by the starter. An example of the course of current during the engine crankshaft driving is shown in Fig. 7.

The condition of the engine in terms of its resistance torque can be determined by comparing the value of the 
resistance torque determined during experiment (driving the crankshaft) and on the basis of the analytical formula.

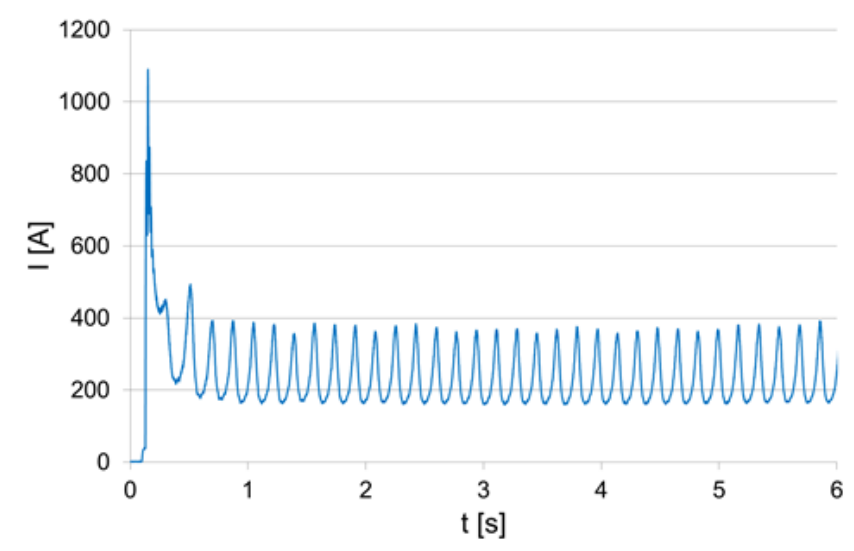

Fig. 7. The course of the current taken by the starter during the engine crankshaft driving

The voltage at the battery terminals characterizes its ability to give off energy. At a given current consumption, the voltage at the battery terminals depends on its nominal capacity $\mathrm{Q}$, the electrolyte temperature $\mathrm{T}$ and the battery state $\mathrm{k}$, which can be identified with the technical condition of the energy source. The voltage on the battery terminals $U$ dependence on the characterizing its state parameters can be assumed as a linear function of these parameters. Battery condition assessment can be made based on comparison the voltage values in engine crankshaft driving conditions and determined from the analytical model. An example of the voltage course at the battery terminals while driving the engine crankshaft is shown in Fig. 8.

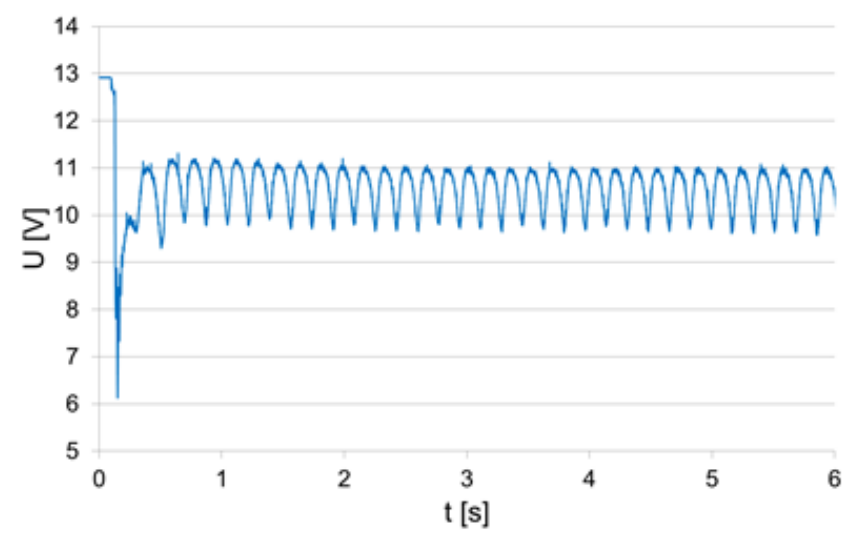

Fig. 8. The course of voltage measured at the terminals of a loaded battery

To assess the state of the electric starter, it is necessary to know the engine resistance torque. The basic meaning in the proposed method of the starter state assessment is to determine its actual power characteristic. The course of the power characteristics of the starter similar to the parabola indicates the possibility of their description using the second-degree polynomial in depending on the current.

The value of engine crankshaft rotational speed driven by the starting system can be used to determine the actual starter power, if its torque value is determined on the basis of the current. The power of the starter in given operating conditions is the basic parameter of the assessment of its technical condition (it must be related to its actual power characteristic). An example of the course of rotational speed of the engine crankshaft driven by starter is shown in Fig. 9.

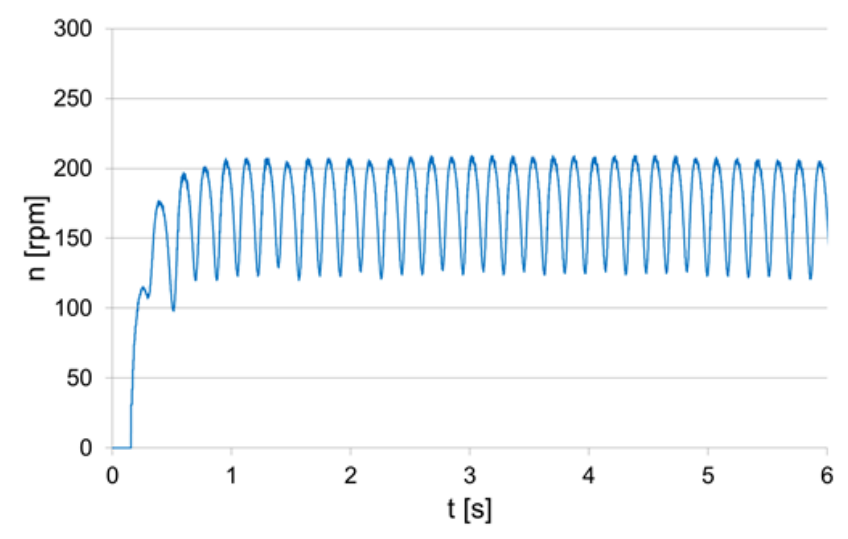

Fig. 9. The course of the engine crankshaft rotational speed driven by the starting system

The signals of the engine crankshaft driving through the electric starting system show significant similarities and correspondence of their variability phases. This is due to the existence of causal relationships between their values resulting from:

- battery characteristics, as a voltage source of electric current, which relate to one another recorded courses of voltage and current,

- a set of starter characteristics, as an electric motor, which uniquely bind the torque of force with the current and rotation speed of the starter shaft with the voltage of the power source.

\section{Closing remarks}

The article presents the principles of the author's own model for calculating the parameters of the cylinder charge while driving the crankshaft by the starting system and the essence of the new proposed system diagnostic method: acid battery - electric starter - internal combustion engine with the use of models of the diagnosed objects.

The mathematical model of any technical object or process presents its formalized, simplified description. The model can replace a real object or a process in such way that its testing can be the source of additional information on the object. The model allows controlling extortion parameters and conditions of object operation and to obtain information and dependencies, measuring of which during the experiment can be impossible, laborious or costly. The goal of working out of the presented model is to assist in experimental studies and to obtain dependencies, which are not provided by an experiment. The presented design for computing of thermodynamic air parameters in engine cranking conditions can be a part of the whole engine startup or diagnostic model. The model should be still developed to increase its accuracy and to close computational procedures to the real conditions of engine driving. First of all, it is necessary to take into account the crankshaft speed non-uniformity. The Woschni formula seems to be the best for surface film conductance evaluation in engine cylinder 
in cranking conditions. The air flow through the pistoncylinder group leakage, due to high pressure difference between cylinder volume and the engine crankcase should be treated as supercritical compressible fluid flow and described using expression (7). The presently obtained results indicate that these data can be used to qualitative and quantitative evaluation of piston engines starting and at the engine diagnostic process.

The originality of the diagnostic method lies in the fact that it enables the assessment of the complete system condi- tion, and above all, the determination of the absolute value of the charge compression pressure in the cylinder. The principle of the relative compression test is based on tracking the battery current, voltage or crankshaft rotational speed changes during cranking to determine the comparative compression values of all cylinders. Proposed method requires the construction and integration into one whole of mathematical models of the battery, electric starter, cylinder charge compression and a model of resistance to driving the crankshaft by the starting system.

\section{Nomenclature}

$\mathrm{dU}$ air charge internal energy change

dQ the exchanged heat quantity
pdV elementary work of volume change

$\mathrm{T}$ temperature

\section{Bibliography}

[1] DIATLOV, E.G., ROMANOV, G.I. Influence of the reduced compression ratio on the starting qualities of a highspeed diesel engine. Engine building. 1990, 7. (In Russian).

[2] CHANG, J., GURALP, O., FILIPI, Z. et al. New heat transfer correlation for an HCCI engine derived from measurements of instantaneous surface heat flux. SAE Technical Paper 2004-01-2996, 2004.

https://doi.org/10.4271/2004-01-2996

[3] DENG, Y., LIU, H., ZHAO, X. et al. Effects of cold start control strategy on cold start performance of the diesel engine based on a comprehensive preheat diesel engine model. Applied Energy. 2018, 210, 279-287. https://doi.org/10.1016/j.apenergy.2017.10.093.

[4] DROŹDZIEL, P. Rozruch samochodowego silnika o zapłonie samoczynnym. Politechnika Lubelska. Lublin 2020.

[5] GARDNER, T.P., HENEIN, N.A. Diesel starting. A mathematical model. SAE Technical Paper 880426. 1988. https://doi.org/10.4271/880426

[6] HEINLE, M., BARGENDE, M., BERNER, H. Some useful additions to calculate the wall heat losses in real cycle simulations. SAE International Journal of Engines. 2012, 5(2), 469-482. https://doi.org/10.4271/2012-01-0673

[7] Compression test using battery voltage waveform during cranking. https://patents.google.com/patent/US4126037A/en (accessed on 05.08.2021).

[8] JORGENSEN, S. Compression temperatures in a cold cranking engine. SAE Technical Paper 880045. 1988. https://doi.org/10.4271/880045.

[9] KASIMOV, A., KORYTCHENKO, K., DUBININ, D. et al. Numerical study of the process of compressing a turbulized two-temperature air charge in the diesel engine. EasternEuropean Journal of Enterprise Technologies. 2018, 6(5), 96, 49-53. https://doi.org/10.15587/1729-4061.2018.150376
[10] KOSZAŁKA, G. Model of operational changes in the combustion chamber tightness of a diesel engine. Eksploatacja i Niezawodnosc - Maintenance and Reliability. 2014, 16(1), 133-139.

[11] LEWICKI, J. Bilans cieplny silnika wysokoprężnego przy rozruchu w niskich temperaturach otoczenia. Prace Naukowe Politechniki Szczecińskiej. 1991, 439.

[12] MOLLENHAUER, K., TSCHÖKE, H. Handbook of diesel engines. Springer Verlag. Berlin, Heidelberg 2010.

[13] MYSŁOWSKI, J. Rozruch silników samochodowych z zapłonem samoczynnym. Wydawnictwo Naukowo-Techniczne. Warszawa 1996.

[14] MYSŁOWSKI, J., TALAGA, K. Thermal loads of a piston in a diesel engine during startup. Combustion Engines. 2008, 133(2), 20-25. https://doi.org/10.19206/CE-117242

[15] TRAWIŃSKI, G. Analiza możliwości wykorzystania pomiarów chwilowej prędkości obrotowej i przyspieszenia wału korbowego do oceny stanu technicznego silnika o zapłonie samoczynnym. Rozprawa doktorska. Wojskowa Akademia Techniczna. Warszawa 2004.

[16] WIŚNIEWSKI, S. Obciążenia cieplne silników tłokowych. Wydawnictwa Komunikacji i Łączności. Warszawa 1972.

[17] WIŚNIEWSKI, S. Termodynamika techniczna. Wydawnictwo Naukowo-Techniczne. Warszawa 1980.

[18] ZHDANOVSKY, N.S., NIKOLAENKO, A.I., KUZMIN, G.S. Thermodynamic analysis of final compression parameters at start-up of a diesel engine. Energomashinostroenie. 1973, 8.

[19] ŽÁK, Z., EMRICH, M., TAKÁTS, M. et al. In-cylinder heat transfer modelling. Journal of Middle European Construction and Design of Cars. 2016, 14(3), 2-10. https://doi.org/10.1515/mecdc-2016-0009

\footnotetext{
Józef Pszczółkowski, DSc., DEng. - Faculty of Mechanical Engineering, Military University of Technology.

e-mail: jozef.pszczolkowski@wat.edu.pl
}

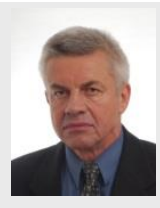

